\title{
Portfolio selection between rational and behavioral theories emergent markets case
}

\author{
Ezzeddine Ben Mohamed and Bouri Abdelfatteh
}

Unit of research COFFIT Sfax Tunisia

\begin{tabular}{|c|c|}
\hline A R T I C L E I N F O & A B S T R A C T \\
\hline $\begin{array}{l}\text { Article history: } \\
\text { Received October 1, } 2011 \\
\text { Received in Revised form } \\
\text { November, 14, } 2011 \\
\text { Accepted 15 February } 2012 \\
\text { Available online } \\
\text { 29 February } 2012 \\
\text { Keywords: } \\
\text { Mean-variance portfolio choice } \\
\text { Behavioral portfolio choice } \\
\text { Determinants of portfolio choice } \\
\text { Cognitive maps }\end{array}$ & $\begin{array}{l}\text { The aim of this paper is to explore the determinants of Portfolio Choice under the investors, } \\
\text { professionals and academics' perception. We introduce an approach based on cognitive } \\
\text { mapping technique with a series of semi-directive interviews. Among a sample of } 30 \text { Tunisian } \\
\text { individuals, we propose tow different frameworks: a mean-variance framework and a } \\
\text { behavioral framework. Each framework is oriented to capture the effect of some concepts as } \\
\text { proposed by the mean-variance portfolio theory and the behavioral portfolio theory on the } \\
\text { portfolio choice decision. The originality of this research paper is guaranteed since it traits the } \\
\text { behavioral portfolio choice in emergent markets. In the best of our knowledge this is the first } \\
\text { study in the Tunisian context that explores such area of research } \\
\text { Ours results show that the Tunisian investors behave as it prescribed by the behavioral portfolio } \\
\text { theory. They use some concepts proposed by the rational mean-variance theory of portfolio } \\
\text { choice but they are affected by their emotions and some others cognitive bias when } \\
\text { constructing and managing they portfolio of assets. }\end{array}$ \\
\hline
\end{tabular}

\section{Introduction}

In The mean-variance portfolio (Markowitz 1952, 1959), teaches as that the portfolio choice is based on some important concepts. It postulates that the mean (as a measure of return), the variance or the standard deviation (as a measure of volatility) and the covariance between assets are primordial. In a mean-variance framework essentially the concept of portfolio diversification and the attitudes to consider the portfolio as a whole are important. In a mean-variance theory investors are supposed to be fully rational when constructing their portfolios.

Beyond the mean-variance framework, empirical and experimental researches argue that (Kahneman \& Tversky, 1979) investors are normal (Statman, 2005) and they are affected by their psychology when they make decisions. This is the beginning of a new approach: the behavioral finance. Shefrin and Statman (2000), formulate the "Behavioral Portfolio Theory". In this behavioral framework,

\footnotetext{
* Corresponding author. Tel: +216 97770781

E-mail addresses: benmohamed.ezzeddine@yahoo.fr (E. B. Mohamed) 
many new concepts are attractable in term of behavioral portfolio choice. Emotions, the safety aim, the potential aim, mental accounting and risk preferences are the most dominated notion in this new frame work. The financial literature is silent about the real world of investors' portfolio practice in emergent markets. Especially, Africa is still an attractive context to test the implications of these two theories of portfolio choice since it still unexplored zone in this area of research.

There are two specific objectives of this study. Firstly, we intend to propose a methodology based on cognitive mapping to detect the effect of the mean-variance concepts on portfolio choice decision among investors, professionals and academics' perception. Then we use the same methodology in a behavioral framework to delimit the behavioral determinants of portfolio choice. The remainder of this paper is organized as follows. In the second section we provide a review of the literature on the portfolio theories concept. The third deals with methodological details which include data description and the analysis method. Section four discusses the empirical results. The fifth section generates the empirical implications of our study. Finally, the sixth section offers concluding remarks and discusses implications of our findings.

\section{Literature review}

In financial literature, the rational mean-variance theory of portfolio choice, as prescribed by Markowitz (1952, 1959), is considered as the best approach for the construction and the management of assets. It proposes some quantitative tools such as the mean and the standard deviation to respectively measure the return and the risk of portfolio. The covariance is an important concept since it is very close to the diversification concept.

In a rational framework of portfolio choice, investors act as if they are fully rational. At each time t, investors try to choose stocks that maximize their utility function. This is will be an easier task when using the mean-variance optimizer (Statman, 2005). However, Markowitz themselves do not follow this men-variance approach (Statman, 2005). The emergence of the behavioural finance should integrate, in the domain of portfolio management, new dimensions such as investors' psychology (Kahneman \& Tversky, 1979, 1991) and emotions (Lopes, 1987). This is the centre of the Behavioral Portfolio Theory (Shefrin \& Statman, 2000). This new theory supposes the normality of investors. In their decision making, investors are affected by some psychological biases.

From a behavioural point of view, emotions such as hope and fear can affect investor's wealth allocation. This is by the creation of a safety aim excess or a potential aim excess. The Hope emotion may lead to an excess of a "potential aim". In this case, investor will be more attracted to invest on risky assets such as stocks with the highest level of risk and so that can normally generate high return. Inversely, the Fear emotion generates an excess of a "safety aim". In term of portfolio choice, an investor who presents an excess of a safety aim should react as it prescribed by Roy (1952). According to Roy (1952), safety first investor trays to minimize the probability of ruin, it means the probability that his final wealth falls short of a subsistence levels.

In their descriptive theory, Shefrin and Statman $(2000,2003)$ introduce the mental accounting bias effect. The mental accounting concept has been first used by Thaler (1980). He affirms that the mental accounting attempts to describe the process whereby people code, categorize and evaluate economic outcome. Investors use different mental account and each one has a specific aim. For example, an investor may distinguish between the "safety aim" and the "potential aim". In fact, the behavioural portfolio as initiated by Shefrin and Statman (2000) has the form of a pyramid with two layers. The downside layer's aim is the protection from poverty. And it is a logic answer to the safety aim. The second one is the upside layer with a potential aim's. Each layer has a specific account and the covariance between layers is overlooked (Shefrin \& Statman, 2003). A tentative reading and analysis for the cited theories of portfolio choice proves that each one have some basic concepts that govern the portfolio choice' decision. Table 1 summarizes the basic concepts for each theory. 
Table 1

The mean-variance and the behavioral theories of portfolio choice' concepts

Mean-variance approach: Expected return, Standard deviation, Covariance, Diversification, Risk

Behavioral approach: Emotions, Safety aim, Potential aim, Experience, gains, losses, Risk, Mental accounting

The mean-variance theory of portfolio choice offered the first systematic treatment of a dilemma that each investor faces: the conflicting objectives of high profit versus low risk (Steinbach, 2001). Markowitz proposes some quantitative tools to build and manage portfolios. The variance as a measure of risk and the expected return as a measure of return help investors on their portfolio's decision. The covariance between assets and the diversification level are practical tools to manage investor's portfolio. The literature revue argues that these concepts are the basis of the rational meanvariance theory of portfolio choice (Markowitz 1952, 1959). These concepts facilitate the portfolio choice's decisions. Statman (2005) describes the mean-variance technique as "a practical tool” that aim to help investors to overlap their cognitive bias.

An alternative to the mean-variance theory is the behavioral one (Shefrin \& Statman, 2000). It is on the basis of some psychological concepts. It is a theory that aims to integrate the role of behavioral concepts. Namely, the "emotions", "safety aim", "potential aim" and "mental accounting” "gains" "losses" and "risk" can be considered as the basic concepts in this new framework of portfolio choice.

One important question is who derives the portfolio choice in emergent markets context? Is it a rational or a behavioral choice?

\section{Materials and method}

We use in this study the cognitive mapping technique. Axelrod (1976) introduces the cognitive maps as a formal way to model decision making in social-economic and politic systems. According to Eden (2004) the cognitive map is a representation of how humans think about a particular issue this is guaranteed by analyzing, arranging the problems and graphically mapping concepts that are interconnected. In addition, it identifies causes and effects and explains causal links. The cognitive maps study perceptions about the world and the way they act to reach human desires with- in their world (Bueno \& Salmeron, 2009). A cognitive map is a mental representation of a person's environment, relied upon during way finding (Sharlin et al., 2009). It may be also defined as a set of cause-effect relationships where the impact produced by the change of one or several elements over the whole system is studied (Koulouriotis et al., 2003).

In his pioneering paper, Tolman (1948) argues that rats, like humans, have a mental representation of the world he called a cognitive map. These maps hold detailed spatial information that individuals collect, integrate and us e while interacting with the environment. Tolman's work has led to the modern psychological definition of a cognitive map: an overall mental image or representation of the space and layout of a setting (Arthur \& Passini, 1992). Cognitive maps possess, as their main limitation the impossibility of quantifying relationships among variables (Bueno \& Salmeron.2009). In the literature review, we can speak in term of individual or aggregate cognitive map.

The individual cognitive map refers to a simple representation of one individual's point of view while the aggregate cognitive map is the sum of more than one person' point of view. According to Weick and Bougon (1986), we can identify three different categories of aggregate cognitive map. We basis our study on the average cognitive map, it is the case when concepts and connections between them are determined with a questionnaire. The questionnaire includes some predefined concepts and the respondent is invited to establish the relationships between concepts (example: see Bougon et al., 
1977). In aggregate cognitive map; a number of associated individuals tray to discuss in a common vision. Generally, it is the case when managers discuss the firm's strategy (see Eden \& Ackermann, 1998).

\subsection{The sample}

Our sample includes 30 interviewees ( 10 investors, 10 academics and 10 professionals). To guaranty the heterogeneity of our sample we use some criterions as the investor's age, education levels, experience, gender, investor's wage and familial situation. Our choice can be justified by the fact that these criterions affect the cognitive and the psychology of an investor.

\subsection{The method}

At the beginning of each interview, we present the aim of our study. We use a semi-directive interview. Each investor was invited to talk about the 12 concepts (variance, covariance, expected return, diversification, emotions, safety aim, potential aim and the mental accounting, experience, risk, gains and losses). The discussion cover the meaning of these concepts from the investor's point of view and whether they affect or not their portfolio choice. After that, we invite each investor to draw his own cognitive map. A paper with the different cited concepts was distributed and he will link between concepts that can have a relationship between them. He will indicate the orientation of each relationship. The intensity a relationship between two concepts A and B can be week (with a value of 1), moderate (2) or strong (3). During the interview process, we ask investors about any relationship that seemed illogically. We introduce the causal algebra as a tool to recapitulate the different relations that can be shown between concepts. Essentially we use addition as a tool for simplifying a direct relation between two concepts.

\subsection{The inter-map analysis}

We follow Prigent et al. (2008) to aggregate the cognitive maps; where the cognitive maps of the interviewees were aggregated by metiers (in our case metiers are: investors, professionals and academics) to form average maps. Eden et al. (1979) suggest that the aim of the aggregation of several cognitive maps is to yield a better representation of the phenomena. It helps us to identify the similarities and differences of perception among metiers.

It is crucial to transform individual maps into adjacency matrices of the form $A=\left[a_{i j}\right]$. The adjacency matrices indicate if a generic concept $C_{i}$ influences a generic concept $C_{j}$. The value of $a_{i j}$ will be 0 in the special case where the generic concept $C_{i}$ has no influence on a generic concept $C_{j}$. It should take the value of the strength of the link between both concepts in case of the presence of an influence between these two variables. To obtain an average cognitive map we calculate the arithmetic mean of the adjacency matrix. In our study, we use the centrality analysis to detect the more significant concepts that affect the portfolio choice according to different point of view. A concept $\mathrm{C}$ is a central concept if it has an important links with other concepts. The centrality analysis is a crucial tool to measure the weight of the influence of a concept c on the portfolio choice decision.

\section{Results}

\subsection{The rational theory: the mean-variance framework}

\subsubsection{Investors' perception}

The adjacency matrix and the cognitive map 
The adjacency matrix given in Table 2 is dominated by the zero-value. Investors are unable to establish links between all the mean-variance concepts. However, we see an intense relationship between the concepts of risk and diversification. The discussion with some investors in our sample approves that they appreciate the effect of the diversification strategy on the risk limitation.

\section{Table 2}

The adjacency matrix of Tunisian investors in a mean-variance framework

\begin{tabular}{lllllll}
\hline $\mathrm{C}_{\mathrm{i}}, \mathrm{C}_{\mathrm{j}}$ & P. Choice & Variance & Covariance & Risk & E. Return & Diversification \\
\hline P. Choice & 0 & 0 & 0 & 0 & 0 & 0 \\
Variance & -2 & 0 & 0 & 0 & 0 & 0 \\
Covariance & 0 & 0 & 0 & 0 & 0 & 0 \\
Risk & -3 & 0 & 0 & 0 & 0 & +2 \\
E. Return & +3 & 0 & 0 & 0 & 0 & 0 \\
Diversificat. & 0 & 0 & 0 & -3 & 0 & 0 \\
\hline
\end{tabular}

Fig. 1 represents the aggregated cognitive map of the Tunisian investors. In the rational framework, the cognitive map isn't very complex. The risk, the expected return and the variance have a direct effect on the portfolio choice. The risk and the variance are negatively related to this choice. The concept of covariance is considered as an exogenous variable that hasn't any influence when choosing between assets.

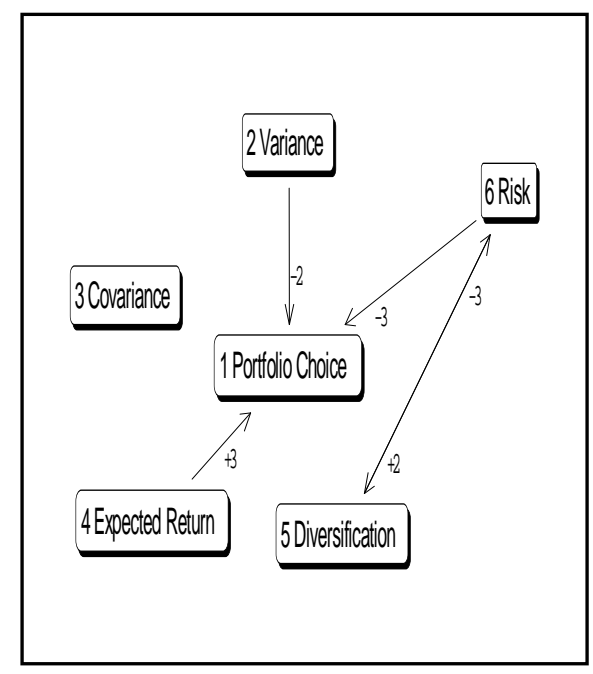

Fig. 1. The aggregated cognitive map of the Tunisian investors in a mean-variance framework

The simplicity of this cognitive map reflects the low level of financial education on the domain of portfolio management of the Tunisian investors. Thing explains the absence of relationships between the technical terms variance, covariance and expected return.

\subsection{The centrality analysis}

The centrality analysis (Table 3) shows that the risk and return are the most important concepts. The concept "risk" exerts a direct influence on the portfolio choice and on the diversification level. It is also influenced by the diversification concept. The majority of interviewees are aware that the diversification affects negatively the risk of their portfolio. This analysis shows also that the Tunisian investors are governed essentially by the risk of an asset more than it expected return. They neglect the role of covariance on the portfolio selection process. This may explain the low score of centrality: it has no connection with any other concept. This term is absent in the cognitive schema of the Tunisian investors. 
Table 3

The centrality analysis (investors’ perception)

\begin{tabular}{lllll}
\hline Risk & Expected Return & Variance & Diversification & Covariance \\
\hline 2 from 5 concepts & 1 from 5 concepts & 1 from 5 concepts & 1 from 5 concepts & 0 from 5 concepts \\
\hline
\end{tabular}

\subsubsection{Professionals’ perception}

The adjacency matrix

The adjacency matrix (Table 4) shows the precence of all the basics concepts prescribed in a the mean-variance approach of Marckowitz (1952) in the cognitive schema of the Tunisian professionals.

Table 4

The adjacency matrix (Tunisian Professionals’ perception)

\begin{tabular}{|c|c|c|c|c|c|c|}
\hline $\mathrm{C}_{\mathrm{i}}, \mathrm{C}_{\mathrm{j}}$ & $\begin{array}{l}\text { Portfolio } \\
\text { choice }\end{array}$ & Variance & Covariance & Risk & Expected Return & Diversification \\
\hline Portfolio choice & 0 & \pm 3 & 0 & \pm 3 & \pm 3 & \pm 3 \\
\hline Variance & -3 & 0 & 0 & +3 & -3 & +2 \\
\hline Covariance & \pm 3 & 0 & 0 & \pm 3 & \pm 3 & \pm 3 \\
\hline Risk & -3 & +3 & \pm 3 & 0 & -3 & +2 \\
\hline Expected R. & +2 & 0 & 0 & 0 & 0 & 0 \\
\hline Diversification & +2 & -3 & +3 & -3 & +2 & 0 \\
\hline
\end{tabular}

The portfolio selection process includes the Expected return of assets and their risk (which can be measured by the variance). The concepts "Diversification" and "Covariances" are seemed to be significiant in a mean-variance model for the portfolio choice. The professionalism of the respondent has a positive effect on the number of connections between concepts. They are aware that the portfolio choice may affect some concepts such as the risk and the variance. The utility of the portfolio diversification is very clear in their cognition. In their parole, they affirm that "If the diversification level isn't enough, it may be a source of risk”. A new relationships raise up between the diversification concept and the covariance one.

\subsection{The cognitive map}

In contrast to the cognitive map of investors, the professionals' cognitive map is more complicated (Fig. 2). It is caracterized by an important number of connections between the mean-variance concepts. The risk, the variance and the covariance are a primordial factors that can affect the portfolio selection.

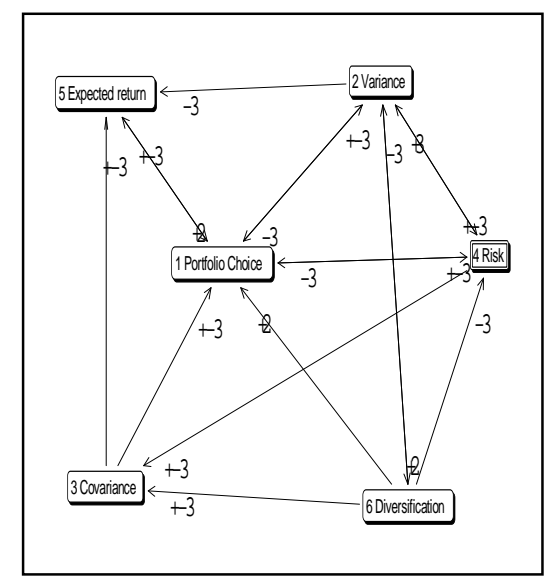

Fig. 2. The professionals' cognitive map in a mean-variance framework of portfolio choice 
From the professionals ' point of view, the risk is strongly and negatively linked with the portfolio selection. This means that they may exclude assets with a hight level of risk. In contrast, the expected return has a positive and moderate influence on the portfolio choice. They prefer assets with hight return and lower risk and they are attracted by the mean-variance approach of portfolio management.

\subsection{The centrality analysis}

The centrality analysis given in Table 5 indicates that the professionals consider that all the meanvariance concepts are centrals and influence the portfolio choice. The conventional approach of Marckowitz (1952) is a theory for risk-averse people (Statman, 2005). We have 4 concepts from 5 in our model that refers to the concept of risk (Risk, Diversification, Covariance and the Variance).

Table 5

The centrality analysis ( The professionals ‘ perception)

\begin{tabular}{lllll}
\hline Risk & Expected Return & Variance & Diversification & Covariance \\
\hline 4 from 5 concepts & 3 from 5 concepts & 4 from 5 concepts & 4 from 5 concepts & 4 from 5 concepts \\
\hline
\end{tabular}

The results of the centrality analysis and the complexity of the cognitive map of the professionals in the mean-variance model let us suggest that the professionals mainly behave according to the meanvariance approach. The diversification is a primordial concept "it's a tool to minimize the risk".

\subsection{Academics’ perception}

\section{The adjacency matrix and the cognitive map}

Table 6 and Fig. 3 represent the aggregated adjacency matrix and the aggregated cognitive map of academics from our sample. The variance and the risk have a strong and negative influence on the portfolio choice. While, the expected return is perceived positively. The academics point of view is on harmony with the predictions of the mean-variance approach.

The risk increases with the variance and decreases with the diversification level. They agree that they should diversify their portfolios in order to avoid a high level of risk. They are well educated by the Marckowitz approach. The risk and the variance are interrelated on their cognitive schema.

\section{Table 6}

The adjacency matrix according to Tunisian Academics

\begin{tabular}{lcccccc}
\hline $\mathrm{C}_{\mathrm{i}}, \mathrm{C}_{\mathrm{i}}$ & Portfolio choice & Variance & Covariance & Risk & Expected Return & Diversification \\
\hline Portfolio choice & 0 & 0 & 0 & 0 & 0 & 0 \\
Variance & -3 & 0 & 0 & +3 & +2 & 0 \\
Covariance & \pm 1 & 0 & 0 & 0 & 0 & 0 \\
Risk & -3 & +3 & 0 & 0 & 0 & +2 \\
Expected Return & +3 & 0 & 0 & 0 & 0 & 0 \\
Diversification & +2 & 0 & 0 & -3 & 0 & 0 \\
\hline
\end{tabular}

The respondents indicate that the variance has a moderate and positive influence on the expected return. They confirm that the variance is a measure of risk. An augmentation of the variance means in increasing of the risk level. They refer to the ACPM; where an increasing of the risk level should be accompanied by an increasing of the expected return. 


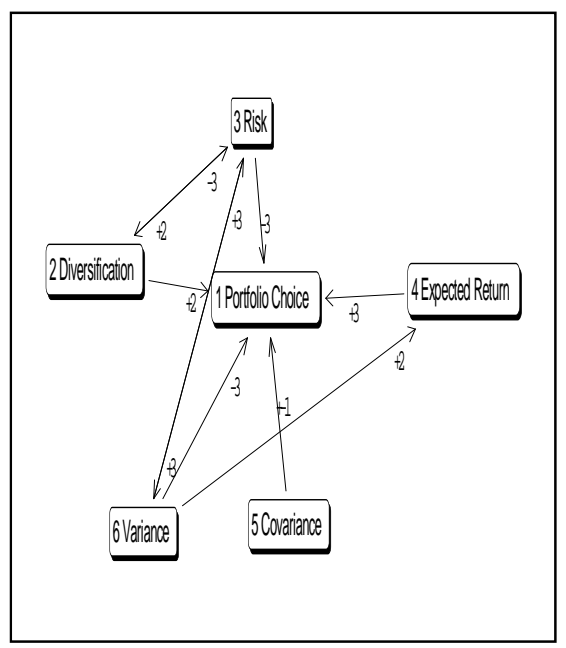

Fig. 3. The Academics' aggregated cognitive map in a mean-variance framework

\subsection{The centrality analysis}

The centrality analysis (Table 7) shows that the academics are governed essentially by the risk and the variance when constructing their portfolio. The expected return, the covariance between assets and the diversification are less significant.

\section{Table 7}

The centrality analysis according to the Tunisian Academics

\begin{tabular}{lllll}
\hline Risk & Expected Return & Variance & Diversification & Covariance \\
\hline 3 from 5 concepts & 2 from 5 concepts & 3 from 5 concepts & 2 from 5 concepts & 1 from 5 concepts \\
\hline
\end{tabular}

\subsection{The behavioural framework}

Investors' perception

The adjacency matrix and the cognitive map

It seems that the different behavioral concepts influence the investor's portfolio choice. The majority of respondents agree that losses affect negatively this choice. This influence goes into a value of -3 . Emotions and mental accounting can have a moderate influence on this choice, but the sign of this relationship isn’t clear. It may affect positively or negatively their choices.

\section{Table 8}

The adjacency matrix of Tunisian Investors in a behavioral framework

\begin{tabular}{lccccccccc}
\hline$C_{i} C_{j}$ & BPC & Emo. & Expe. & Gains & Losses & Mental Ac. & Safety & Potential & Risk \\
\hline BPC & 0 & 0 & 0 & 0 & 0 & 0 & 0 & 0 & 0 \\
Emotions & \pm 2 & 0 & 0 & 0 & 0 & 0 & \pm 2 & \pm 2 & 0 \\
Experience & +2 & +2 & 0 & +2 & -3 & +2 & 0 & +2 & 0 \\
Gains & +2 & +2 & 0 & 0 & 0 & +2 & 0 & +2 & 0 \\
Losses & -3 & -3 & 0 & 0 & 0 & -3 & 0 & 0 & 0 \\
Mental accounting & \pm 2 & \pm 2 & 0 & 0 & 0 & 0 & \pm 2 & \pm 2 & 0 \\
Safety aim & +2 & 0 & 0 & 0 & -3 & 0 & 0 & 0 & 0 \\
Potential aim & +2 & 0 & 0 & +2 & 0 & 0 & 0 & 0 & 0 \\
Risk & -3 & -3 & 0 & -3 & +2 & -3 & +2 & -3 & 0 \\
\hline
\end{tabular}


The "Experience" and "Risk" affect some other concepts but they aren't influenced by any one of them. Investors think that the risk is an exogenous variable and it cannot be influenced by others variables that belongs to the behavioral model. The experience may be explained by other variable such as the age of investors. The emotions may cause potential or safety aims. Our finding confirms the SP/A two factors theory predictions. In her theory, Lopes (1987) demonstrate that emotions (Fear and Hope) stimulate the emergence of such aims. In term of portfolio choice, the safety aim may lead to the decreasing of losses (the influence is intense ant it takes a negative sign [-3]). In contrast, the potential aim affects positively the gains concept. The mental accounting bias is an active concept on the behavioral framework of portfolio selection. This bias can be strongly and negatively affected by the risk and losses concepts. In this case, the investor will be essentially governed by the safety aim. However, if the mental accounting bias is stimulated by a large experience of investment or by gains, it will probably the origin of potential aim. The investor's cognitive map (Fig. 4.) is a complicated one. This may due to the important number of connections between the concepts of the behavioral model.

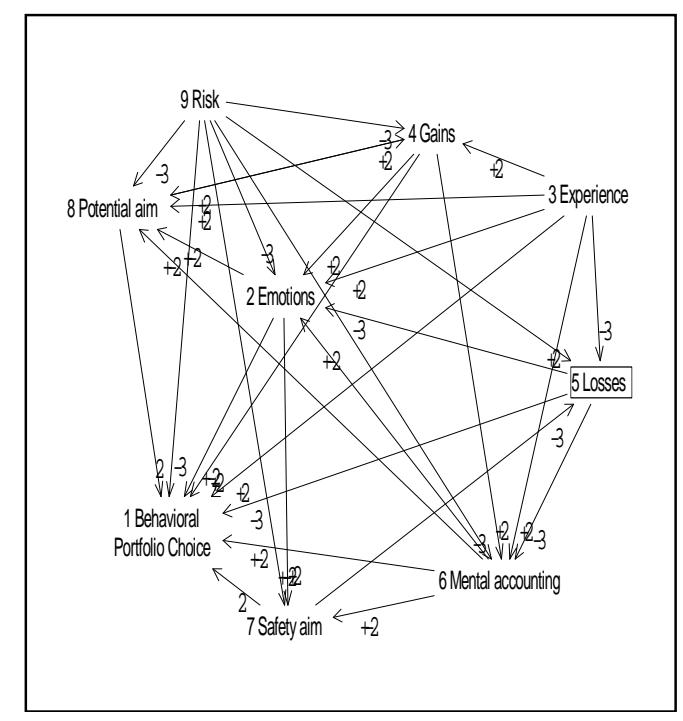

Fig. 4. The aggregated cognitive map of investors in a behavioral model

\subsection{The centrality analysis}

We find that the emotions and the mental accounting are the most significant concepts in the behavioral model (Table 9). All the other concepts are also seem to be central . Ours results corroborate the theoretical predictions of Shefrin and Statman (2000). In the BPT Emotions is a central concept. According to Lopez (1987), Emotions can influence the attitude toward risk. So, it may affect the Behavioral Portfolio Choice: the fear pushes an investor to react as if he was risk averse. On term of portfolio choice, this investor will be attracted by safety assets. While, an investor who is governed by the hope's emotion, will be normally more attracted by risky assets.

\section{Table 9}

The centrality analysis in a behavioral framework

\begin{tabular}{|c|c|c|c|c|c|c|c|}
\hline Emc & $\begin{array}{l}\text { Mental } \\
\text { accounting }\end{array}$ & Risk & $\begin{array}{l}\text { Potential } \\
\text { aim }\end{array}$ & $\mathrm{a}$ & S & $\mathrm{Fx}$ & $\begin{array}{l}\text { Safety } \\
\text { aim }\end{array}$ \\
\hline $\begin{array}{l}8 \mathrm{fl} \\
\text { conc }\end{array}$ & $\begin{array}{l}8 \text { from } \\
\text { concepts }\end{array}$ & $\begin{array}{l}7 \text { from } 8 \\
\text { concepts }\end{array}$ & $\begin{array}{l}7 \text { from } 8 \\
\text { concepts }\end{array}$ & $\begin{array}{l}7 \text { from } \\
\text { concepts } \\
\end{array}$ & & $\begin{array}{l}6 \text { from } \\
\text { concepts }\end{array}$ & \\
\hline
\end{tabular}




\subsection{The professionals' perception}

The adjacency matrix and the cognitive map

The experience, the gains and the safety aim exert a positive effect on the behavioral portfolio choice. While, the losses and risk concepts are negatively perceived (Table 10). They affirm that "the behavioral portfolio choice may be the origin of future gains or losses”.

Table 10

The adjacency matrix in a behavioral framework: Investors' perception

\begin{tabular}{lccccccccc}
\hline $\mathrm{C}_{\mathrm{i}}, \mathrm{C}_{\mathrm{j}}$ & BPC & Emot. & Exper & Gains & Losses & Mental Ac. & Saf. & Pot. aim & Risk \\
\hline BPC & 0 & 0 & 0 & \pm 1 & \pm 1 & \pm 1 & 0 & 0 & 0 \\
Emotions & \pm 1 & 0 & 0 & 0 & 0 & 0 & \pm 1 & \pm 1 & \pm 1 \\
Experience & +2 & 0 & 0 & 0 & -2 & 0 & \pm 1 & 0 & -2 \\
Gains & +2 & 0 & 0 & 0 & 0 & +2 & -2 & 0 & 0 \\
Losses & -3 & 0 & 0 & 0 & 0 & -3 & +2 & 0 & 0 \\
Mental Ac. & \pm 1 & \pm 1 & 0 & \pm 1 & \pm 1 & 0 & 0 & 0 & 0 \\
Safety aim & +2 & 0 & 0 & 0 & -2 & 0 & 0 & 0 & -2 \\
Pot. Aim & \pm 1 & 0 & 0 & 0 & +2 & 0 & -2 & 0 & +2 \\
Risk & -3 & 0 & 0 & -3 & +2 & 0 & +2 & 0 & 0 \\
\hline
\end{tabular}

The "experience" is a transmitter concept. It affects other variables but it doesn't receive any influence from other concepts. We find that the emotions and the mental accounting may affect positively or negatively the portfolio choice. For example, if a professional is dominated by the fear emotion. He will be not able to seize some opportunity with a higher risk and which can generate a higher gains. In their perception, the mental accounting is a function of the gains and losses . We find also an asymmetric perception of the gains and losses effect on the mental accounting. They more appreciate the effect of losses (intensely affects the mental accounting bias). They claim that "when the risk level increases, we should refer to the classical tools to decide where to invest and with which weight in each asset. The mental account biases should be ignored when the decision's context is a risky one. The risk has a negative influence on gains. In contrast, he may contribute to the increasing of losses (+2) and he stimulated the professionals to concentrate on the safety aim. The concept "risk" is sensible to the professionals' emotions. If an individual is governed by the hope emotion, then he will feel more comfortable with an increasing of the risk level. In contrast, someone who presents a fear emotion will aim normally to reduce his risk level. The professionals experience seems having a negative impact on the risk concept.

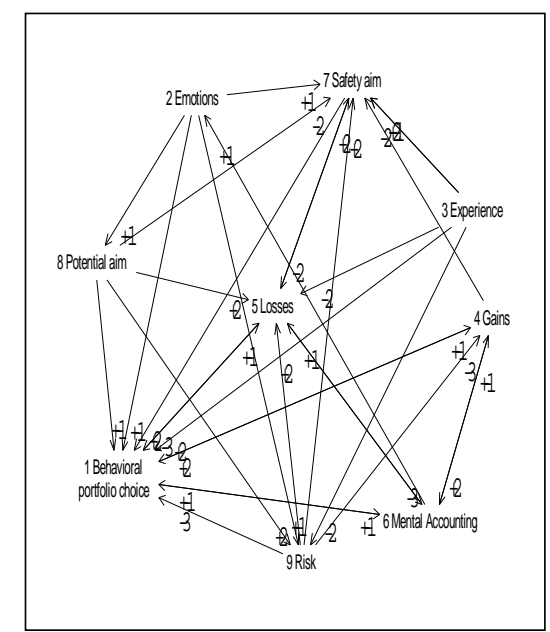

Fig. 5. The Tunisian Professionals' agregated cognitive map in a behavioral framework of portfolio choice 
We can see (Fig. 5) that, in some strength, all the behavioral concepts are interrelated. The experience is characterized as transmitter concepts. We note the existence of a concentration of links around the concepts of risk, losses and safety aim. In fact, these concepts are theoretically interrelated.

\subsection{The centrality analysis}

In a behavioral framework, the professionals are governed essentially by three concepts: the risk, the safety aim and the losses (Table 11). The Tunisian professionals belongs to the "safety first" investors. They try to reduce the risk of their portfolio in order to minimize their losses. We observe also that the concept "losses" is more central than the "gains" concept.

Table 11

The centrality analysis

\begin{tabular}{llllllllllll}
\hline Risk & Safety aim & Losses & Emotions & $\begin{array}{l}\text { Potential } \\
\text { aim }\end{array}$ & $\begin{array}{l}\text { Mental } \\
\text { accounting }\end{array}$ & Gains & Experience \\
\hline 7 from 8 & 7 & from 8 & 6 from 8 & 5 from 8 & $\begin{array}{l}5 \text { from } 8 \\
\text { concepts } \\
\text { concepts }\end{array}$ & $\begin{array}{l}4 \text { from } 8 \\
\text { concepts } \\
\text { concepts } \\
\text { concepts }\end{array}$ concepts & $\begin{array}{l}4 \text { from } 8 \\
\text { concepts }\end{array}$ & $\begin{array}{l}\text { from } \\
\text { concepts }\end{array}$ \\
\hline
\end{tabular}

\subsection{Academics' perception}

\section{The adjacency matrix and the cognitive map}

The adjacency matrix in Table 12 generates the perception of the academics in a behavioral framework of portfolio choice. We show that the experience exerts a negative impact on emotions. The academics affirm that "If we have a good experience, we don't need to use our emotions". The risk affect all the behavioral concepts (unless the experience and the mental accounting). Academics indicate that the mental accounting bias is used only when they realise losses. The cognitive schema of the Tunisian academics indicates their tendency to associate the "safety aim" concept with "the potential aim" concept. Each one of them affects negatively the other concept. The SP/A two factor's theory affect the portfolios risk. The safety aim may reduce the risk by investing on safety assets. While the potential aim may contributes to an increasing of the risk level.

Table 12

The adjacency matrix in a behavioral framework: Academics' perception

\begin{tabular}{lccccccccc}
\hline $\mathrm{C}_{\mathrm{i}}, \mathrm{C}_{\mathrm{j}}$ & BPC & Emot. & Exper & Gains & Losses & Mental Ac. & Saf. & Pot. aim & Risk \\
\hline BPC & 0 & 0 & 0 & 0 & 0 & 0 & 0 & 0 & 0 \\
Emotions & \pm 2 & 0 & 0 & 0 & 0 & 0 & 0 & 0 & 0 \\
Experience & +2 & -2 & 0 & 0 & 0 & 0 & 0 & 0 & 0 \\
Gains & +2 & 0 & 0 & 0 & 0 & 0 & 0 & 0 & 0 \\
Losses & -3 & 0 & 0 & 0 & 0 & +2 & 0 & 0 & 0 \\
Mental Ac. & \pm 2 & 0 & 0 & 0 & 0 & 0 & 0 & 0 & 0 \\
Safety aim & \pm 2 & 0 & 0 & 0 & 0 & 0 & 0 & -2 & -2 \\
Pot. Aim & \pm 2 & 0 & 0 & 0 & 0 & 0 & -2 & 0 & +2 \\
Risk & -3 & \pm 2 & 0 & -3 & +2 & 0 & +2 & -3 & 0 \\
\hline
\end{tabular}

The mental accounting may influence the behavioral portfolio choice. This influence is moderate and it can be negative or positive. The safety aim and the potential aim are interrelated. And the presence of one of them has a negative effect on the other one. 


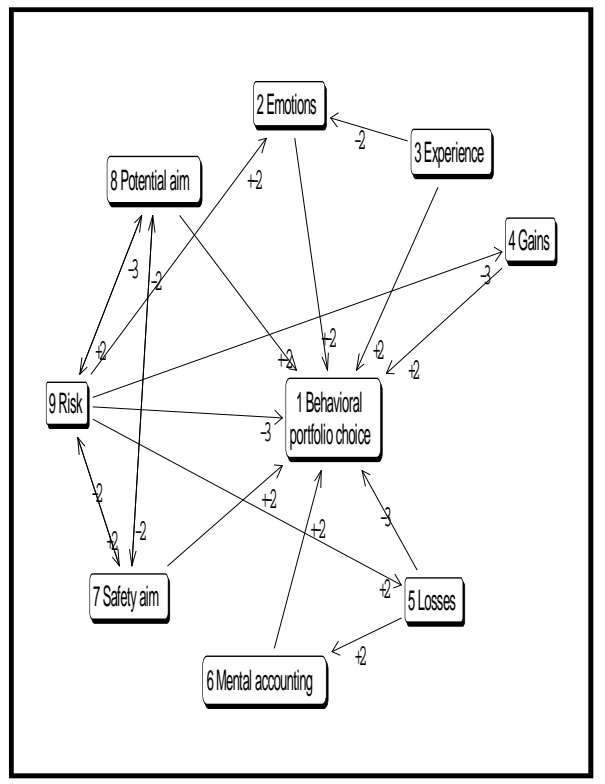

Fig. 6. The aggregated cognitive map of Academic in a behavioral framework

The aggregated cognitive map (Fig. 6) isn't very complex. Our results let us suggesting that the academics are attracted to the mean-variance approach. They know all details concerning this theory.

\subsection{The centrality analysis}

Table 13 generates the results of the centrality analysis. In a behavioral framework, the risk is the more important concept. The potential aim, the safety aim and the losses concepts may be considered also as central concepts. Emotions are relatively less significant. This result is logic: academics are very qualified in the domain of portfolio management. This is why they consider that the emotions are less significant in the behavioral portfolio framework. The "experience" and the "mental accounting bias” aren't very active concepts in the behavioral portfolio framework. In some strength, they are neutral concepts. This explains the existence of a few numbers of connections around them.

Table 13

The centrality analysis

\begin{tabular}{llllllllll}
\hline Risk & $\begin{array}{l}\text { Potential } \\
\text { aim }\end{array}$ & $\begin{array}{l}\text { Safety } \\
\text { aim }\end{array}$ & Losses & Emotions & Gains & Experience & $\begin{array}{l}\text { Mental } \\
\text { accounting }\end{array}$ \\
\hline $\begin{array}{l}\text { 6 from } 8 \\
\text { concepts }\end{array}$ & $\begin{array}{l}3 \text { from } \\
\text { concepts }\end{array}$ & $\begin{array}{l}3 \text { from } 8 \\
\text { concepts }\end{array}$ & $\begin{array}{l}2 \text { from } 8 \\
\text { concepts }\end{array}$ & $\begin{array}{l}3 \text { from } 8 \\
\text { concepts }\end{array}$ & $\begin{array}{l}2 \text { from } 8 \\
\text { concepts }\end{array}$ & $\begin{array}{l}2 \text { from } 8 \\
\text { concepts }\end{array}$ & $\begin{array}{l}2 \text { from } 8 \\
\text { concepts }\end{array}$ \\
\hline
\end{tabular}

\section{Discussions}

In a mean-variance approach, the risk and the expected return seem central concepts. The risk is perceived negatively, while the expected return is always positively perceived. The concept of covariance has no meaning in the mind of investors. This concept can largely affect the portfolio choice according to the professionals' point of view. Only investors consider that the diversification has an indirect impact on the portfolio choice. We note also that, the concepts of the rational theory of portfolio choice are very clear in the cognition of the academics. This is because they have a solid theoretical formation in the domain of portfolio management.

In a behavioral framework, the risk stills a central concept. It is always perceived negatively by all the categories in our sample. It is a mean-variance concept but it belongs also to the behavioral portfolio 
theory's concepts. The respondents consider that the experience exerts a positive influence on the portfolio choice. The emotions, the safety aim, the potential aim, the mental accounting, the losses and gains can largely affect the behavioral portfolio choice.

\section{Conclusion}

We aim to study the portfolio choice according to different points of views. Our sample was segmented by metiers. We investigate the investors, professionals and academic's perception on portfolio choice. The cognitive map seems an attractive technique since it can give us a clear representation of the different links between portfolio concepts.

Two models are used. The mean-variance model teaches us that the Marckowitz version of portfolio choice is very clear for the academics and the professionals. While, investors seem to be attached to the expected return, the risk and the variance. The concept of covariance is ignored by Tunisian investors. This is may be due to its complexity. In general, we find that the mean-variance concepts are relatively significant in the portfolio choice process. The behavioral model shows that the basics concepts of the behavioral portfolio theory can be considered as central in the behavioral framework of portfolio choice.

The risk and the expected return serve as practical tools on the portfolio selection process. But some behavioral variables, the investors' experience, the mental accounting, the safety aim and the potential aim... seem to be central in the cognition of the Tunisian investors. Our results confirm that "Investors are normal" as it predicted by Statman (2005). They use the mean-variance statistical tools but they are affected by their psychology and emotions and financial advisors should take this reality when they construct individual portfolio for their investors.

\section{References}

Arthur, P., \& R. Passini, (1992). Way finding: people, signs and architecture. New York: Mac GrawHill Ryerson.

Axelord, R. (1976). Structure of Decision: the Cognitive Maps of Political Elites. Princeton University, NJ.

Bougon, M., Weick, K., \& Binkhorst, D. (1977). Cognition in organization: an analysis of the Utrecht Jazz Orchestra. Administrative Science Quarterly. 22, 606-639.

Bueno, S., \& Salmeron, J.L. (2009). Benchmarking main activation functions in fuzzy cognitive maps2. Expert Systems with Applicattions. 36, 5221-5229.

Eden, C., \& Ackermann, F. (1998). Making Strategy. The journey of Strategic Management, SAGE Publications, London, UK, ISBN 0-7619-5525-X

Eden, C. (2004). Analyzing cognitive maps to help structure or problems. European Journal of Operational Research. 159, 673-686.

Kaheneman, D., Knetsch, J.L., \& Thaler, R. (1991). Anomalies: The endowment effect, Loss aversion, and status quo bias. The Journal of Economic Perspectives. 5(1), 193-206.

Kahneman, D., \& Teversky, A. (1979). Prospect Theory: Analysis Decision Making Under Risk. Econometrica. 47, 263-291.

Koulouriotis, D.E., Diakoulakis, I.E., Emiris, D.M., Antonidakis, E.N., \& Kaliakatsos, I.A. (2003). Efficiently modeling and controlling complex dynamic systems using evolutionary fuzzy cognitive maps. International Journal of Computational Cognition. 1, 41-65. 
Lopes, L. (1987). Between hope and fear: The psychology of risk. Advances in Experimental Social Psychology. 20, 255-295.

Markowitz, H. M. (1959). Portfolio Selection: Diversification of Investments. New York: Jhon Wiley and Sons.

Markowitz, H. M. (1952). Portfolio Selection. Journal of Finance. 7, 77-91.

Prigent et al. (2008). Using cognitive maps to investigate fishers' ecosystem objectives and knowledge. Ocean and Costal Management. 51, 450-462.

Sharlin et al. (2009). A tangible user interface for assessing cognitive mapping ability. International Journal of Human-Computer Studies. 67, 269-278.

Shefrin, H., \& M. Statman, (2000). Behavioral portfolio theory. Journal of Financial and Quantitative Analyses, 35, 127-151.

Statman, M. (2005). What Is Behavioral Finance?. An Interview With Meir Statman. Industry Trend. The Monitor.

Thaler, R. (1985). Mental accounting and consumer choice. Marketing Science. 4, 199-215.

Thaler, R. (1999). The end of behavioral finance. Financial Analysts Journal. 55, 12-17.

Tolman, E.C. (1948). Cognitive maps in rats and men. Psychological Review. 55, 189-208.

Von Neumann, J., \& Morgenstern, O. (1947). Theory of games and economic behavior. Princeton, NJ: Princeton University Press.

Weick, K.E., \& Bougon, M.G. (1986). Organisation as cognitive maps: Charting ways to success and failure. The thinking organization: Dynamics of organizational social. San Francisco, Jossey Bass Publishers, 102-13 